\title{
Identification and selection of potential sites for onshore wind farms development in Region of Murcia, Spain
}

\author{
J.M. Sánchez-Lozano ${ }^{\text {a, }}{ }$, M.S. García-Cascales ${ }^{\text {b }}$, M.T. Lamata ${ }^{\text {c }}$ \\ a Centro Universitario de la Defensa de San Javier, Academia General del Aire, Universidad Politécnica de Cartagena (UPCT), Murcia, Spain \\ ${ }^{\mathrm{b}}$ Depto de Electrónica. Tecnología de Computadoras y Proyectos, Universidad Politécnica de Cartagena (UPCT), Murcia, Spain \\ ${ }^{\mathrm{c}}$ Depto de Ciencias de la Computación e Inteligencia Artificial, Universidad de Granada, Granada, Spain
}

\section{A R T I C L E I N F O}

\section{Article history:}

Received 19 September 2013

Received in revised form 4 June 2014

Accepted 7 June 2014

Available online $\mathrm{xxx}$

\section{Keywords:}

Onshore wind farms

Geographic Information Systems GIS

Restrictions

Criteria

Lexicographic order

ELECTRE-TRI

\begin{abstract}
A B S T R A C T
It is often advisable to combine spatial representation tools such as Geographic Information Systems (GIS) with Multi criteria Decision Making Methods (MCDM) when solving location complex problems. The current case refers to the search for and selection of sites for onshore wind farms on the coast of the Region of Murcia, in the southeast of Spain. When resolving the proposed problem, the legal restrictions and the criteria (wind speed, area, slope, etc.) that influence the location will be considered. These will be defined in the form of thematic layers that will be entered into the GIS. Restrictions will be imposed taking into account the legislative framework of the study area so that, through their analysis and editing, it will be possible to reduce the initial area and obtain suitable sites where this type of facilities can be installed. Moreover, as the objective of the study is to select the locations and obtain a ranking two different models will be applied, initially a categorical assessment through a lexicographic order will be performed using the tools available in the GIS and, later it will be applied the ELECTRE-TRI methodology will be applied in order to make a comparison between the methods.
\end{abstract}

(c) 2014 Elsevier Ltd. All rights reserved.

\section{Introduction}

The objective of reducing the emissions of gases that cause the greenhouse effect [1], has led to significant energy policies being established to promote the implementation of renewable energies both globally [2-7] and at European level [8-10]. The development and promotion of such facilities was not a priority for many countries [11], whilst in others (Spain, Germany, the United States, etc.) their implementation has extended spectacularly as a result of the momentum and adoption of energy support policies [12-14]. Such policies allowed the generation of both direct and indirect employment [15], even though in their research and development such facilities were unable to achieve high efficiencies [16]. Today, most governments have reduced support for renewable energy facilities because of the financial and economic crisis; however, the growth of these facilities has increased significantly, driven both by a stable market [17], and by decreasing production costs [18].

In Spain, in order to fulfill the targets set by the international community, energy plans $[19,20]$ were developed that

\footnotetext{
* Corresponding author. Tel./fax: +34 968189914

E-mail address: juanmi.sanchez@cud.upct.es (J.M. Sánchez-Lozano).
}

encouraged the promotion of renewable energies; with wind energy being the resource that experienced the greatest growth. At the end of 2010, Spain was - in terms of installed wind power - the fourth global wind power, and the second in Europe [21]. However, due to the current economic crisis and the uncertainty created by changes in the Spanish legislative framework [22], public and private investment has been reduced. This meant that at European level in 2012, Spain had fallen to fourth place [23] with a market share of $9 \%$ compared to other EU member states (Fig. 1). This nevertheless helped to improve the control of external energy dependence [24]. Therefore, given that Spain has a wind potential of $330 \mathrm{GW}$, it is necessary to continue promoting and encouraging the implementation of wind energy facilities in order to comply with the international legislative framework and to reach the $35 \mathrm{GW}$ of accumulated wind power laid down as a specific target for 2020 [20,25].

Although the Region of Murcia, in the southeast of Spain, has a wind potential of $2.9 \mathrm{GW}$ [26], the coast or littoral is an area with a high level of urban and residential occupation [27]. This increases the difficulty for any promoter of renewable energy facilities to find areas where it is possible to implement this type of facilities. Therefore, when designing wind farms not only will it be necessary to take into account factors that optimize performance [28-31] but 


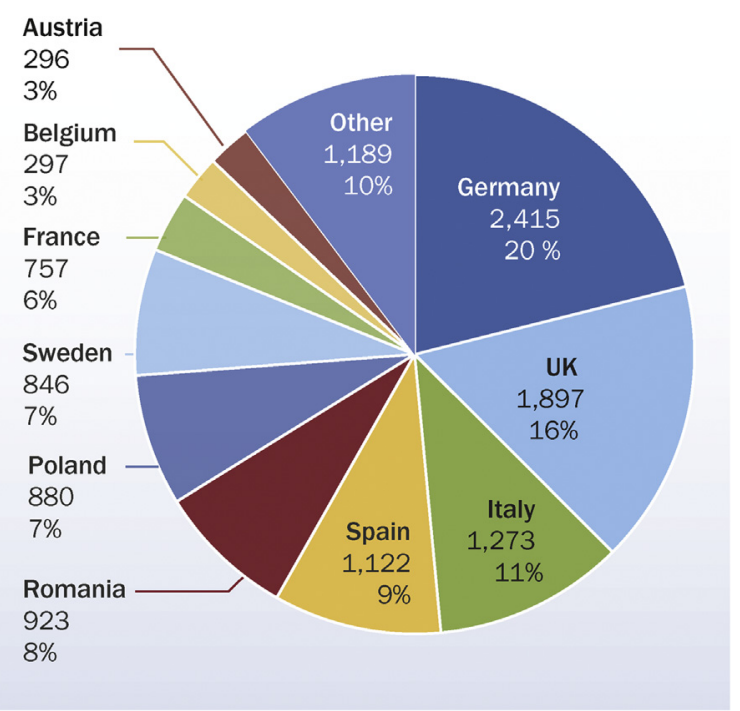

Fig. 1. EU Member State market shares for new wind power capacity installed during 2012 in MW [23].

it is also of great interest to conduct studies which appraise both the restrictions as well as the criteria that influence the location of onshore wind farms, with the aim of finding and selecting the best sites.

In most cases, due to the high number of possibilities and criteria involved in the decision, to solve such problems it is appropriate to apply multi criteria decision methods (MCDM) so appropriate methodologies must be built in the scientific field of the matter to be resolved [32]. Although in the 1990s studies in decision support methodologies in the field of renewable energies began [33,34], it was not until the early 21 st century when this type of analysis was expanded as a result of the existence of a legislative framework favorable to such energy. The analytic network process (ANP) was applied to evaluate energy policy in Turkey [35]; in the same country a multi attribute selection was also conducted among renewable energy alternatives using fuzzy analytic hierarchy process (AHP) [36] and an integrated fuzzy VIKOR \& AHP methodology [37]. More recently a review of multi criteria decision making methods for bio energy systems [38] has been carried out and, through a combination of fuzzy AHP and TOPSIS manufacturing technologies of photovoltaic solar cells [39] and thermal power plant location [40] have been evaluated. This brief review demonstrates the excellent utility of using MCDM in the field of renewable energies. Moreover, selecting locations normally involves conditions that limit the implementation and expansion of any facility (available surface, distance to substations, etc.), so that analysis should be addressed to optimizing the installation, depending on the factors that determine its proper implementation. It is precisely for these reasons that the combination of MCDM with visualization tools and cartographic editions such as Geographic Information Systems (GIS) is very useful [41], as the GIS are capable of generating databases through the analysis and edition of the geospatial information, and decision support systems allow to structure the decision problems and evaluate the alternatives under study [42]. Since they were unveiled, the use of GIS has spread to many areas, including the field of renewable energies [43-47] and when they are combined with multi criteria decision methods they acquire an extraordinary potential [48]: in a region in the west of Turkey a GIS was combined with the OWA operator for the evaluation of wind energy systems [49]. In Oman, the suitability of installing solar photovoltaic plants was also analyzed by mixing a GIS and multi criteria fuzzy methodology (OWA method) [50]. In a region of Italy the availability of biomass was evaluated by combining GIS with AHP [51]. To assess the best locations in photovoltaic solar farms in the south of Spain, the GIS were combined with AHP method [52], with AHP and TOPSIS [53], or more recently by applying the ELECTRE-TRI method using an iterative process through a Decision Support System called IRIS [54].

Although as it has been mentioned before, the ELECTRE-TRI methodology has been used to solve location problems of other renewable technologies [54], there are important differences that make its application in the present study especially novel (Table 1). In Ref. [54] the help of an expert and a decision support system called IRIS based on the pessimistic version of the ELECTRE-TRI method were employed. Through expert recommendations and an iterative process with the IRIS software, a small number of locations of solar farms are classified (through the pessimistic procedure of assignment of categories of the ELECTRE-TRI method) with the aim of obtaining the weights of the criteria from that classification. In the current article not only is the renewable energy technology different but also the manner in which the ELECTRE-TRI method is applied and the process of assigning categories to the different alternatives (in this case the optimistic procedure of the ELECTRE-TRI method will be used). Moreover, the aim is not to obtain the weights of the criteria (these are known previously), but to perform each of the steps that define this method through an Excel spreadsheet to classify all the viable locations by categories.

It is also important to note that being different renewable technologies (photovoltaic solar farms vs. onshore wind farms), the same criteria are not used. There are criteria which are very important to solve location problems of onshore wind farms (distance to airports, wind speed, etc.). However these criteria are not necessary to locate solar farms. Moreover, in the present study not only is the ELECTRE-TRI methodology applied, but also a comparison between two different models (Lexicographic order vs. ELECTRE-TRI) is carried out with the aim of knowing the advantages and disadvantages of applying one methodology or the other.

With this review of the existing literature, the important role played by the combination of GIS with MCDM for the development and promotion of renewable energies can be clearly seen, therefore; in the current work a GIS has been chosen to be used in solving the proposed problem. The GIS employed is a free software

Table 1

Main differences between the present study and previous studies [54].

\begin{tabular}{|c|c|c|}
\hline & Present study & Previous studies [54] \\
\hline ELECTRE-TRI methodology & - Optimistic ELECTRE-TRI procedure is applied & - Pessimistic ELECTRE-TRI procedure is applied \\
\hline $\begin{array}{l}\text { Purpose of applying the } \\
\text { ELECTRE-TRI methodology }\end{array}$ & $\begin{array}{l}\text { - Classify all the potential alternatives (the weights of the criteria } \\
\text { are known) }\end{array}$ & - Obtain the weight of the criteria that influence the decision \\
\hline $\begin{array}{l}\text { Way to implement the } \\
\text { ELECTRE-TRI methodology }\end{array}$ & $\begin{array}{l}\text { - Executing each of the steps that define the ELECTRE-TRI } \\
\text { methodology, thus all the potential alternatives are classified }\end{array}$ & $\begin{array}{l}\text { - Iterative process of the software in which an expert classifies a } \\
\text { small number of alternatives according to his/her opinion }\end{array}$ \\
\hline Software used & - Excel spreadsheet & - Decision Support System called IRIS \\
\hline Software capacity & $\begin{array}{l}\text { - It is possible to analyze a large number of alternatives (in this case } \\
33,290 \text { alternatives) }\end{array}$ & $\begin{array}{l}\text { - The number of alternatives that can be introduced is very } \\
\text { small (20-30 alternatives) }\end{array}$ \\
\hline
\end{tabular}


developed in 2004 by the Regional Ministry of Infrastructure and Transport of Valencia (Spain) called gvSIG [55].

In the present article the GIS will be used to search for and select the best locations to host onshore wind farms on the coast of the Region of Murcia, in the southeast of Spain. The proposed problem (Fig. 2) will be defined in section 2. In this section the viable locations to implement onshore wind farms will be obtained, defining the restrictions which prevent a given area from being valid and taking into account the criteria that influence the decision. Thus, a database of possible locations will have been created which, through the methodology described in section 3, will be evaluated by applying and comparing the two proposed models. An iterative process of filtering based on the criteria will be performed as well as a multi criteria decision analysis through the ELECTRE-TRI method, which will allow the optimal sites to host onshore wind farms to be selected. These analyses will be carried out in section 4. Finally, sections 5 and 6 will reflect the results and the conclusions of the study.

\section{Creation of the database using the GIS tool}

This section contains an explanation of the proposed methodology, which is given in Fig. 2. As can be seen from Fig. 2, the first step is related with feasible locations. To obtain these feasible locations we will rely on the GIS tool and by applying the restrictions set by European Union law as well as Spanish legislation regarding the implementation of renewable energies, the 33,290 feasible plots to implement a wind farm will be obtained. But it is not only necessary to know whether a plot complies or not with the legal requirements, but a database must also be built with ratings based on certain evaluation criteria. Finally, a ranking of these alternatives is required. To achieve this, two very different models will be applied, in the first case an evaluation will be made through a lexicographic order and then an ELECTRE-TRI method will be applied [56].

\subsection{Search for feasible locations}

Not all sites are suitable to implement onshore wind farms. For any territory a series of restrictions and criteria will exist which must be taken into account to choose the correct location; thus the starting point for obtaining the viable locations will be to identify the area of study which, in the proposed problem, corresponds to the coast of the Region of Murcia (Fig. 3). This area covers $4456.59 \mathrm{~km}^{2}$ and is composed of 13 municipalities whose territory is classified into plots and subplots. Once the study area has been defined the process to follow will consist in defining the restrictions i.e., the areas where, because of the current legislative framework, it is not possible to implement facilities. Once the restrictions have been determined, the next step will consist in subtracting the area occupied by the restrictions from the total area of the coast of the Region of Murcia in order to obtain suitable and available locations to implement onshore wind farms.

\subsubsection{Restrictions}

The areas of a territory are not uniform in their suitability to implement renewable energy facilities; anything that might limit the performance of such facilities must be taken into account.

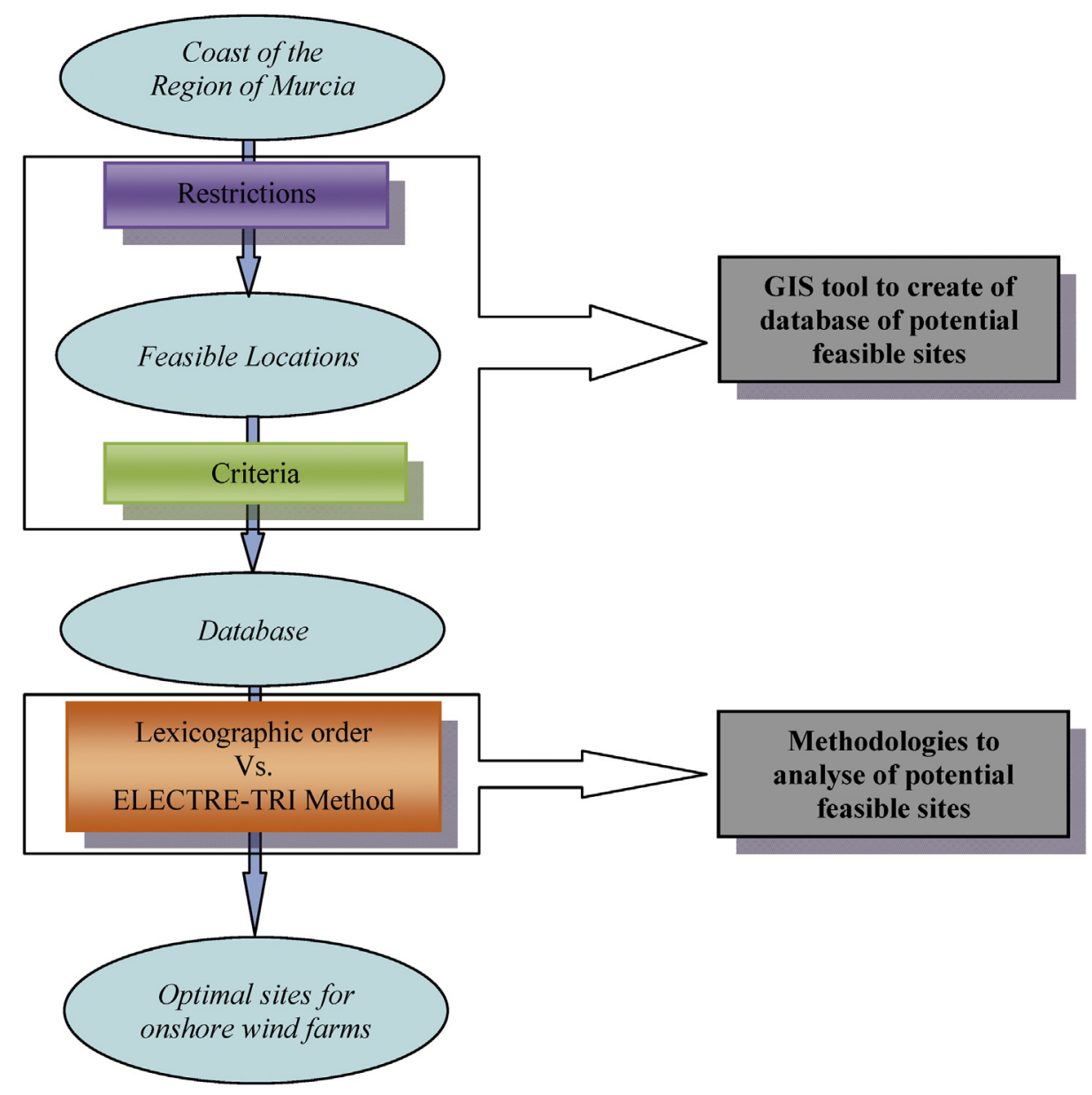

Fig. 2. Process scheme. 


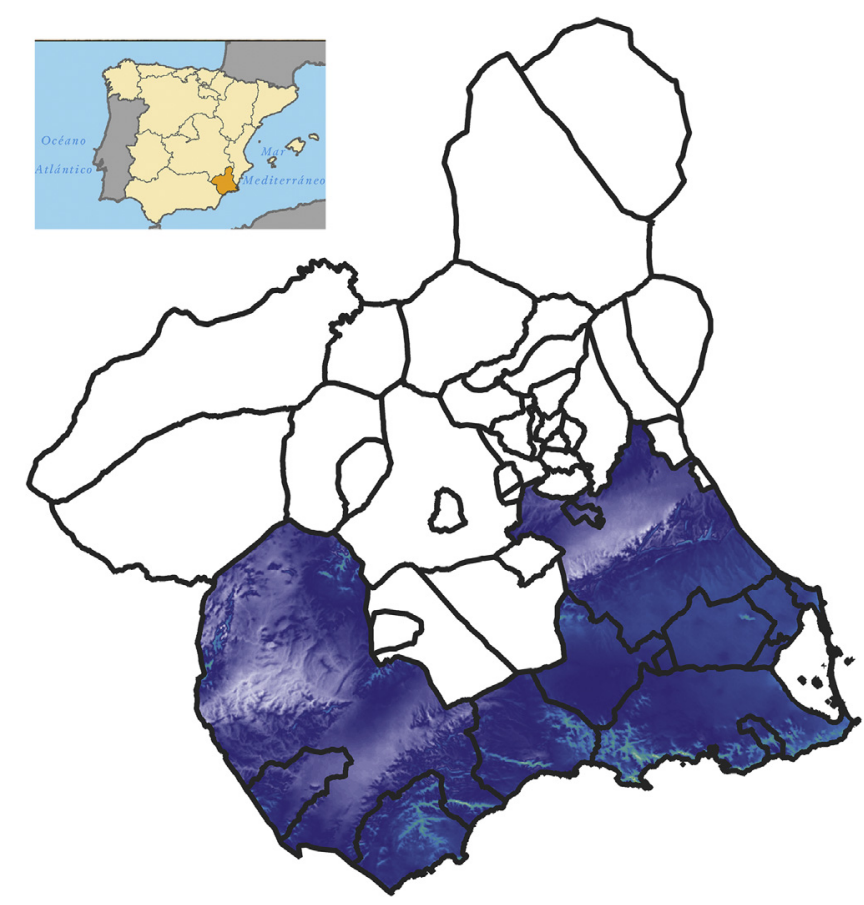

Fig. 3. Coast of the Region of Murcia.

Therefore, once the territory to analyze has been selected, it is necessary to carefully study the current status of that territory (cities, roads, rivers, protected areas, etc.) together with its legal framework (European, national, regional and local legislation) in order to determine the restrictions affecting that territory [49]. On the coast of the Region of Murcia, local policies such as general urban plans, regional policies such as laws of archaeological, cultural and historical heritage, guidelines and territorial planning of industrial land, land law, etc. must all be fulfilled. Furthermore, like any other Spanish territory, it will be affected by national policies such as road law, natural heritage and biodiversity law, coastal law, etc. and finally by European directives on the conservation of natural habitats and of wild fauna and flora [57].

Therefore, analyzing the current state of the study area together with its legal framework, it is possible to determine the restrictions (Table 2), i.e., both for the areas themselves as well as their areas of influence in which it will not be possible to implement renewable energy facilities.

In addition to the above considerations it must be taken into account that to implement wind farms any plot containing some buildings (agricultural warehouse, reservoir, etc.) should be rejected and, considering that according to experts in renewable energy

Table 2

Legal restrictions.

\begin{tabular}{ll}
\hline N. & Denomination of legal restrictions \\
\hline 1 & Urban lands \\
2 & Protected and undeveloped lands \\
3 & Areas of high landscape value \\
4 & Water infrastructure, military zones and cattle trails \\
5 & Watercourses and streams \\
6 & Archaeological sites \\
7 & Paleontological sites \\
8 & Cultural heritage \\
9 & Roads and railroad network \\
10 & Community interest sites (LICs) \\
11 & Areas of special protection for birds (ZEPAs) \\
12 & Mediterranean coast \\
\hline
\end{tabular}

facilities, to implement a wind farm requires a minimum area of $5000 \mathrm{~m}^{2}$, those zones with an area below this size will also be discarded.

\subsubsection{Implementation of restrictions}

To carry out the process of implementation of these restrictions and to obtain available locations the gvSIG software will be used to analyze the territory and the restrictions in the form of thematic layers which will be inserted in gvSIG not only to obtain their display, but also to enable their analysis with the tools of the software itself. These thematic layers have been supplied by the regional government of the Region of Murcia.

Once all the layers in gvSIG have been entered [58], the area occupied by each of the legal restrictions will be subtracted from the initial thematic layer (coast of the Region of Murcia). Subsequently, the remaining territory (sorted into municipalities, plots and subplots) will be filtered to exclude plots below $5000 \mathrm{~m}^{2}$ or those containing any buildings. Once this step has been conducted a new layer representing the viable locations will be obtained (Fig. 4).

Analyzing the information provided by the thematic layer in Fig. 4 it is obtained that, of the entire territory covered by the coast of the Region of Murcia ( $4456.59 \mathrm{~km}^{2}$ ), $19.94 \%$ of that area will be adequate to implement wind farms; this corresponds to a total of $888.75 \mathrm{~km}^{2}$. This area is composed of 33,290 plots and these are the alternatives to analyze i.e., these will be the locations in which it is possible to implement wind farms.

The following steps will consist in selecting, from among the alternatives mentioned, those which are the best to implement this type of facilities, based on a set of criteria.

\subsection{Database of potential sites}

\subsubsection{Criteria}

When implementing renewable energy facilities it must be considered that the analyzed area is not affected by any legal restrictions, but that we must also have a set of criteria that will influence in the decision.

Although research and studies have been conducted that define the characteristics that these criteria must contain [48,59], the choice of these criteria will depend primarily on the study area. Therefore, following the guidelines in Ref. [52] for the particular case under analysis, four groups of general criteria (environment, orography, location and climatology criteria) will be defined which will be decomposed into a specific number of criteria that will influence the location i.e., those that will make one site preferable rather than another (Fig. 5).

Then each of the specific criteria is briefly described [60]:

- $g_{1}$. - Agrological capacity (classes): Suitability of land for agricultural development. If a territory presents excellent agrological capacity (class 0 ) it will not be suitable to host a facility, while if its agrological capacity is low (class 8 ) it will be a very favorable area to implement this type of facilities.

- $g_{2}$. - Slope (\%): Land slope, the greater percentage slope a territory has, the worse aptitude it will have to implement a wind farm.

- $g_{3}$. - Area $\left(\mathrm{m}^{2}\right)$ : The area contained within a perimeter of land that can accommodate a renewable energy facility, the larger an area is, the more attractive it will be to implement onshore wind farms.

- $g_{4 .}$ - Distance to main airports (m): Space or interval between the nearest airport and the different possible sites. In order to not affect airspace or future expansion of airports and facilities 


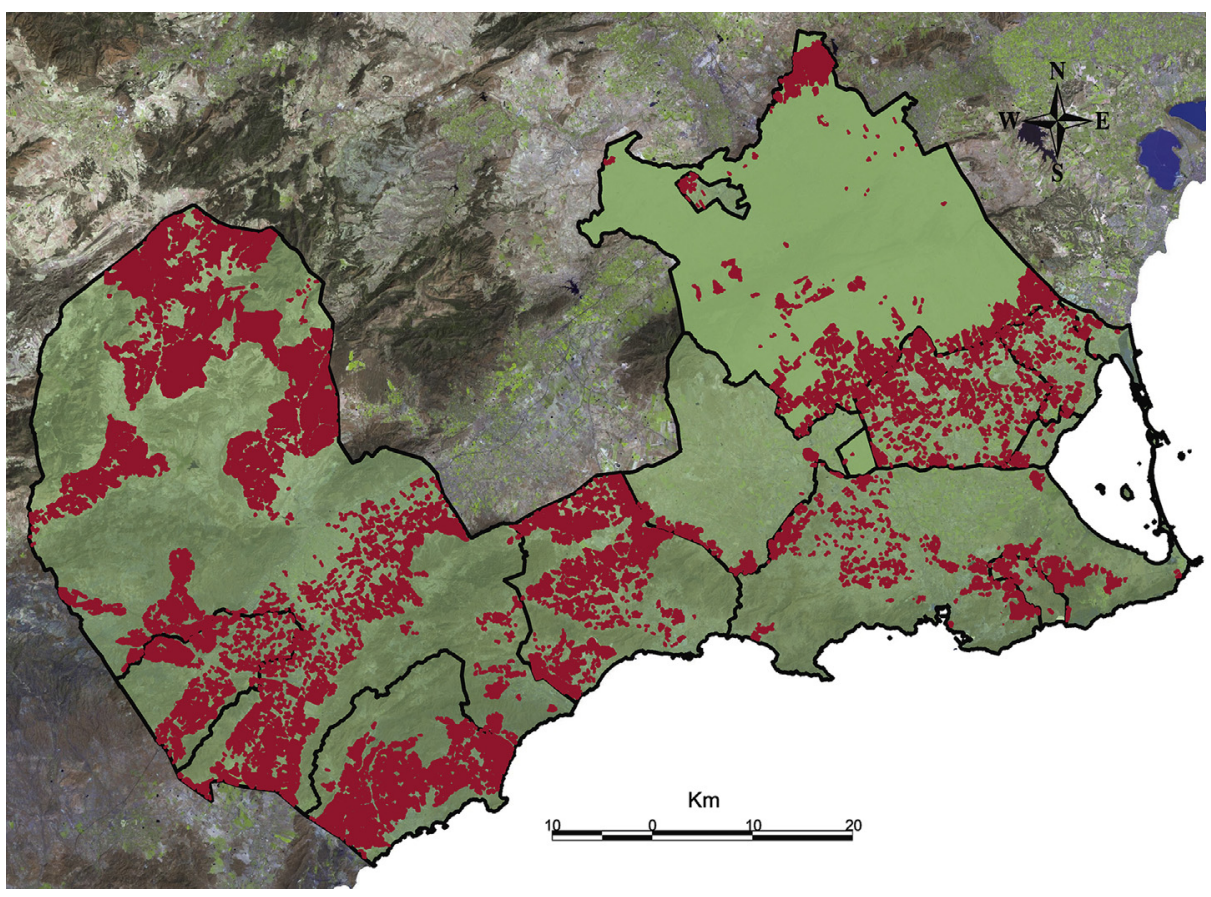

Fig. 4. Thematic layer of viable locations to implement onshore wind farms.

of this type, it is desirable to implement wind farms as far as possible from airports.

- $g_{5}$ - Distance to main roads $(\mathrm{m})$ : Space or interval between the nearest road and the different possible sites. To reduce the transport costs for installation and subsequent maintenance of any renewable energy facility, it will be agreed that the distance to main roads should be short.
- $g_{6} .-$ Distance to power lines ( $\left.\mathrm{m}\right)$ : Space or interval between the nearest grid or power line and the different possible sites. It is desirable that the distance to power lines is the minimum possible because the initial cost is therefore reduced and the efficiency of the facility is increased.

- $g_{7}$. - Distance to cities (m): Space or interval between the population centers (cities or towns) and the different possible

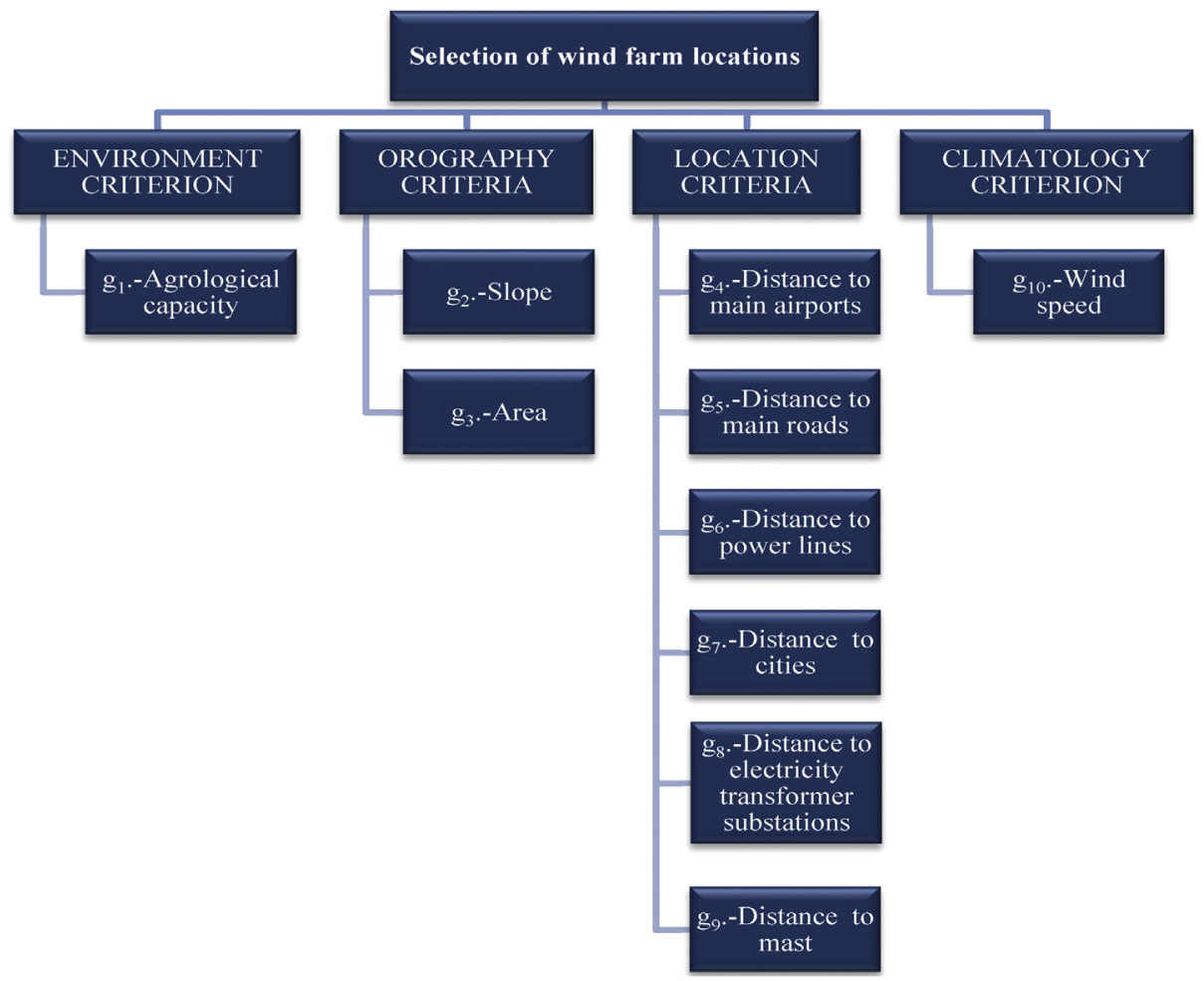

Fig. 5. Criteria tree for selection of wind farm locations. 
Table 3

Boundaries of categories of alternatives $\left(A_{i}\right)$ for each of the criteria.

\begin{tabular}{|c|c|c|c|c|}
\hline Criteria & Category 1 (regular) & Category 2 (good) & Category 3 (very good) & Category 4 (excellent) \\
\hline$g_{1}:$ Agrological Cap. (Classes) & $0<A_{i}<2$ & $2 \leq A_{i}<4$ & $4 \leq A_{i}<7$ & $7 \leq A_{i}<8$ \\
\hline$g_{2}:$ Slope $(\%)$ & $A_{i}>50$ & $50 \geq A_{i}>30$ & $30 \geq A_{i}>15$ & $A_{i} \leq 15$ \\
\hline$g_{3}:$ Area $\left(\mathrm{m}^{2}\right)$ & $A_{i}<10000$ & $10000 \leq A_{i}<300000$ & $300000 \leq A_{i}<1000000$ & $A_{i} \geq 1000000$ \\
\hline$g_{4}:$ Distance to $A_{i}$ rports (m) & $A_{i}<7000$ & $7000 \leq A_{i}<20000$ & $20000 \leq A_{i}<35000$ & $A_{i} \geq 35000$ \\
\hline$g_{5}:$ Dist. to roads (m) & $A_{i}>5000$ & $5000 \geq A_{i}>2000$ & $2000 \geq A_{i}>500$ & $A_{i} \leq 500$ \\
\hline$g_{6}$ : Dist. to power lines (m) & $A_{i}>5000$ & $5000 \geq A_{i}>1500$ & $1500 \geq A_{i}>500$ & $A_{i} \leq 500$ \\
\hline$g_{7}:$ Dist. to cities (m) & $A_{i}<1000$ & $1000 \leq A_{i}<2000$ & $2000 \leq A_{i}<5000$ & $A_{i} \geq 5000$ \\
\hline$g_{8}:$ Dist. to transformer sub. $(\mathrm{m})$ & $A_{i}>5000$ & $5000 \geq A_{i}>1500$ & $1500 \geq A_{i}>500$ & $A_{i} \leq 500$ \\
\hline$g_{9}:$ Dist. to mast (m) & $A_{i}<400$ & $400 \leq A_{i}<1000$ & $1000 \leq A_{i}<4000$ & $A_{i} \geq 4000$ \\
\hline$g_{10}:$ Wind speed $(\mathrm{m} / \mathrm{s})$ & $A_{i}<3.20$ & $3.20 \leq A_{i}<5.50$ & $5.50 \leq A_{i}<7.00$ & $A_{i} \geq 7.00$ \\
\hline
\end{tabular}

sites. Although the conditions indicated in the legislative framework for any territory are fulfilled, it will be advisable not to implement any wind farm near population centers, in anticipation of future expansion of either.

- $g_{8}$. - Distance to electricity transformer substations (m): Space or interval between the different electricity transformer substations and the different possible sites. As with the criterion of distance to power lines, it is preferable that the distance to transformer substations is short.

- $g_{9}$. - Distance to mast (m): Space or interval between any telecommunications infrastructure and the different possible sites. In order to not affect the telecommunications infrastructure or future extensions, it is advisable to implement the wind farm away from these.

- $g_{10}$. - Wind speed $(\mathrm{m} / \mathrm{s})$. It corresponds to the wind speed at a height of $80 \mathrm{~m}$ in the different possible sites. It will be agreed to choose territories whose average wind speeds are high in order to optimize the facility.

\subsubsection{Database}

For the purposes of creating a database with all the alternatives and criteria, the criteria will be treated in a similar manner to that used in the definition of restrictions i.e., they must be introduced into the GIS as thematic layers. Therefore, both the regional government and private companies were requested to provide the thematic layers of the criteria that influence the selection of this type of facilities. Introducing the thematic information for each of the criteria into the GIS in the layer of viable locations previously obtained, new thematic layers will be created which, at first sight appear identical to Fig. 4, although that layer not only represents the 33,290 alternatives to analyze, but is also linked to an attribute table showing the thematic information represented in rows and columns. The rows constitute the geographic objects that in this case will be the alternatives to select (plots) and the columns define the so-called attributes or thematic variables (cadastral information and criteria) forming a matrix with the data for each plot for each of the 10 criteria mentioned.

This attribute table constitutes the database of potential sites. In this table, the potential sites will be selected through a filtering process and a multi criteria decision analysis using the ELECTRE-TRI method.

\section{Methodology}

Once we have the database of the plots based on the 10 criteria described above it is necessary to evaluate the data. So two very different methods have been developed: first, due to its simplicity the lexicographic order will be applied because the wind speed criteria is much more important than the rest (Table 4), and then the ELECTRE-TRI decision method based on preferences will be applied.

\subsection{Preference structure}

We assume that a decision-maker compares two alternatives $A_{i}$ and $A_{j}$, he/she has three possible options; preference $\left(A_{i} P A_{j}\right)$ or indifference $\left(A_{i} I A_{j}\right)$ between them, or that they cannot be compared $\left(A_{j} J A_{j}\right)[61]$.

The following requirements are natural and accepted in the literature:

$$
\begin{aligned}
& A_{i} P A_{j} \Rightarrow A_{j} \not P A_{j}: \text { Pis asymmetric } \forall A_{i}, A_{j} \in \mathrm{A} \\
& A_{i} I A_{j} \quad: \text { I is asymmetric } \forall A_{i}, A_{j} \in \mathrm{A} \\
& A_{i} I A_{j} \Rightarrow A_{j} I A_{j} \quad: \text { I is symmetric } \forall A_{i}, A_{j} \in \mathrm{A} \\
& A_{i} \not \supset A_{i} \quad: \text { Jisirreflexible } \forall A_{i}, A_{j} \in \mathrm{A} \\
& A_{i} J A_{j} \Rightarrow A_{j} \not \supset A_{i}: J \text { is symmetric } \forall A_{i}, A_{j} \in \mathrm{A}
\end{aligned}
$$

and it is necessary to assume that only one of the properties $\left(A_{i} P A_{j}\right)$, $A_{i} I A_{j}, A_{j} J A_{j}$ is true.

\subsection{Lexicographic order}

Taking into account a preference structure [61,62] the lexicographic order will be defined in the same sense as the determined order in a dictionary:

$A_{i}>A_{j} \Leftrightarrow\left\{\begin{array}{l}(a) g_{1}\left(A_{i}\right)>g_{1}\left(A_{j}\right) \\ (b) g_{i}\left(A_{i}\right)=g_{i}\left(A_{j}\right), i=1,2, \ldots, k \text { and } \\ g_{k+1}\left(A_{i}\right)>g_{k+1}\left(A_{j}\right), \text { for some } k=1,2, \ldots, k-1\end{array}\right.$

Ultimately we are assuming that the criteria are arranged in order of importance (Table 4 ). Thus alternative $A_{i}$ is preferred to $A_{j}$ if it has a higher score on $g_{1}$, or if they have equal score to $g_{1}$, its review is better for the following criterion in importance.

\subsection{ELECTRE-TRI method}

ELECTRE-TRI $[56,63,64]$ is a method that assigns predefined categories to a group of alternatives. The assignment of an

Table 4

Order of importance of criteria to implement wind farms [60].

\begin{tabular}{l}
\hline Order of importance of the 10 criteria \\
\hline$g_{10}>>^{*} g_{8}>{ }^{* *} g_{4}>g_{1}>g_{6}>g_{2}=g_{3}>g_{9}>g_{7}>g_{5}$ \\
${ }^{*}>>$ : strongly more important. \\
$*^{* *}>$ : more important.
\end{tabular}


alternative $A$ in one category or another is obtained by comparing this alternative with the limits of predefined categories.

Let $F$ denote the set of criteria $g_{1}, g_{2}, \ldots g_{m}(F=1,2, \ldots, m)$ and $B$ the series limits of the profiles that define $p+1$ categories $(B=\{1$, $2, \ldots, p\})$ with $b_{h}$ being the upper limit of the category $C_{h}$ and the lower limit of the category $C_{h+1}$ with $h=1,2, \ldots, p$. It is possible to represent the limits of the different categories as shown in Fig. 6 , where the boundaries $b_{0}$ and $b_{p+1}$ correspond to anti-ideal and ideal alternatives respectively.

ELECTRE-TRI builds an outranking relation $S$ i.e., it validates or invalidates the assertion $\left(A_{i} S b_{h}\right)$ whose meaning is "alternative $A_{i}$ is at least as good as $b_{h}$ ".

\section{Step 1. Definition of reference actions}

The reference actions are defined as the limits of the different categories that allow classifying the potential actions and the preference $p_{j}\left(b_{h}\right)$ and indifference $q_{j}\left(b_{h}\right)$ thresholds so that $q_{j}\left(b_{h}\right)$ represents the biggest difference $g_{j}\left(A_{i}\right)-g_{j}\left(b_{h}\right)$ that keeps the indifference between $A_{i}$ and $b_{h}$ for the criterion $g_{j}$ and, $p_{j}\left(b_{h}\right)$ represents the smallest difference $g_{j}\left(A_{i}\right)-g_{j}\left(b_{h}\right)$ compatible with a preference of $A_{i}$ on the criterion $g_{j}$. For both thresholds $g_{j}\left(A_{i}\right)$ is the value of the criterion $j$ for the alternative $A_{i}$ and $g_{j}\left(b_{h}\right)$ is the value of the criterion at the upper limit of the category $C_{h}$.

The rest of the defining parameters to implement the method correspond to the weights of the criteria $\left(k_{1}, k_{2}, \ldots k_{m}\right)$ and the veto thresholds $v_{j}\left(b_{h}\right)$ which represent the smallest difference $g_{j}\left(b_{h}\right)-g_{j}$ $\left(A_{i}\right)$ incompatible with the assertion $\left(A_{i} S b_{h}\right)$.

Step 2. Determination of concordance indices by criteria

The concordance index for a given criterion $c_{j}\left(A_{i}, b_{h}\right)$ is defined as follows:

$$
\begin{aligned}
& \begin{array}{l}
c_{j}\left(A_{i}, b_{h}\right)=0 \Leftrightarrow p_{j} \leq g_{j}\left(b_{h}\right)-g_{j}\left(A_{i}\right) \\
\begin{aligned}
0<c_{j}\left(A_{i}, b_{h}\right)<1 \Leftrightarrow q_{j}<g_{j}\left(b_{h}\right)-g_{j}\left(A_{i}\right) \leq p_{j} \\
\end{aligned} \\
\Rightarrow c_{j}\left(A_{i}, b_{h}\right)=\frac{g_{j}\left(A_{i}\right)+p_{j}-g_{j}\left(b_{h}\right)}{p_{j}-q_{j}}
\end{array} \\
& \begin{array}{l}
c_{j}\left(A_{i}, b_{h}\right)=1 \Leftrightarrow g_{j}\left(b_{h}\right)-g_{j}\left(A_{i}\right) \leq q_{j}
\end{array}
\end{aligned}
$$

\section{Step 3. Calculation of the overall concordance}

The overall concordance index $C\left(A_{i}, b_{h}\right)$ will be calculated by the following expression:

$C\left(A_{i}, b_{h}\right)=\frac{\sum_{j \in F} k_{j} \cdot c_{j}\left(A_{i} \cdot b_{h}\right)}{\sum_{j \in F} k_{j}}$

Step 4. Determination of the discordance indices by criteria

The discordance indices $d_{j}\left(A_{i}, b_{h}\right)$ will be calculated according to that expressed in (3):

$$
\begin{aligned}
& d_{j}\left(A_{i}, b_{h}\right)=0 \Leftrightarrow g_{j}\left(A_{i}\right) \geq g_{j}\left(b_{h}\right)-p_{j} \\
& 0<d_{j}\left(A_{i}, b_{h}\right)<1 \Leftrightarrow g_{j}\left(b_{h}\right)-v_{j}<g_{j}\left(A_{i}\right) \leq g_{j}\left(b_{h}\right)-p_{j} \\
& \Rightarrow d_{j}\left(A_{i}, b_{h}\right)=\frac{g_{j}\left(b_{h}\right)-g_{j}\left(A_{i}\right)-p_{j}}{v_{j}-p_{j}} \\
& d_{j}\left(A_{i}, b_{h}\right)=1 \Leftrightarrow g_{j}\left(b_{h}\right)-v_{j}\left(b_{h}\right) \geq g_{j}\left(A_{i}\right)
\end{aligned}
$$
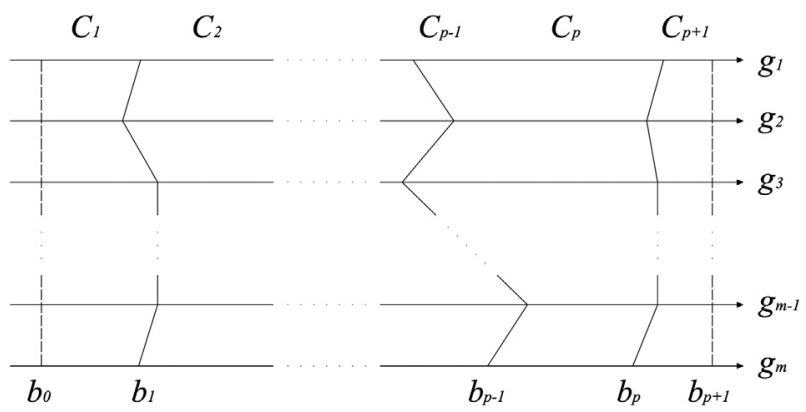

Fig. 6. Definition of the categories using limit profiles.

Step 5. Obtaining the degree of credibility

The degree of credibility $\sigma_{S}$ is given by the following expression (4):

$\sigma_{s}\left(A_{i}, b_{h}\right)=C\left(A_{i}, b_{h}\right) \cdot\left(1-\max _{j \in\{1, \ldots, m\}} d_{j}\left(A_{i}, b_{h}\right)\right)$

Step 6. Determination of the outranking relation

The outranking relation between a potential action $A_{i}$ and a reference action $b_{h}$ is established from the credibility degrees and a constant cutting threshold $\lambda$ that corresponds to the lower value of the degree of credibility from which the assertion $A_{i}$ overcomes $b_{h}$ is valid (i.e., such assertion is corroborated $\left(A_{i} S b_{h}\right)$ when $\sigma_{S}\left(A_{i}, b_{h}\right) \geq \lambda$.

\section{Step 7. Assignment of alternatives to different categories}

Once an alternative $A_{i}$ has been compared to the action or reference profiles $b_{h}$, in ELECTRE-TRI there are two ways to assign an alternative $A_{i}$ to one of the predefined categories:

a) Pessimistic procedure: It consists in assessing $\left(A_{i} S b_{h}\right)$ successively for the different profiles starting with the best profile to find the $b_{h}$ profile for which $\left(A_{i} S b_{h}\right)$ is verified, and once found $A_{i}$ is assigned to the category $C_{h+1}$.

b) Optimistic procedure: It consists in comparing the alternative $A_{i}$ successively with the different profiles starting with the worst profile to find the $b_{h}$ profile for which $\left(A_{i} S b_{h}\right) \wedge\left(b_{h} S A_{i}\right)$, and once found $A_{i}$ is assigned to the category $C_{h}$.

In the present article the optimistic procedure of the ELECTRETRI methodology will be applied through an Excel spreadsheet which allows to perform more complex operations, so it will thus be easier and more efficient to apply it.

\section{Analysis}

\subsection{Lexicographic order}

In the study case, the database created from gvSIG comprises 33,290 alternatives and can obtain the numerical values of all the criteria for each of the alternatives (plots) to select; these values will be used to perform a filtering process according to a classification of alternatives by categories. This is done because an alternative may be found that has the highest rating in the most important criterion and a very low rating in the other criteria and yet according to the lexicographic order be chosen as the best. For that, an expert in wind energy (a doctor engineer with over 10 years 
of experience in the field of renewable energies) was consulted and who indicated not only the number of categories in which the alternatives should be classified according to the 10 criteria, but he also established the boundaries of these categories for each of the criteria. According to this expert, and since all the alternatives are suitable for the implementation of a wind farm, it is possible to classify the alternatives into four categories (category 1 , category 2 , category 3, category 4) according to the aptitude or capacity to host a wind farm (regular, good, very good, and excellent capacity, respectively) and to establish the boundaries (Table 3 ) of these categories according to the domains of the criteria that influence the location.

The selection process consists in progressively removing, through filtering techniques, those alternatives that are located in the lower categories with the aim of obtaining the locations situated in the best categories:

- Filtering $\mathrm{n}^{\circ} 1$. Removing those alternatives that present values in some of their criteria in category 1 . The remaining alternatives will offer good, very good or excellent capacity to host onshore wind farms.

- Filtering $\mathrm{n}^{\circ} 2 \mathrm{~A}$. From the alternatives obtained in filtering $\mathrm{n}^{\circ} 1$, those with values for any of their criteria in category 2 will be removed. The remaining alternatives will be very good or excellent.

- Filtering $\mathrm{n}^{\circ} 2 \mathrm{~B}$. From the alternatives obtained in filtering $\mathrm{n}^{\circ} 2 \mathrm{~A}$, those in which the values of their criteria are in category 3 will be removed. The remaining alternatives will be excellent to host such facilities.

- Filtering $\mathrm{n}^{\circ} 2 \mathrm{C}$. If filtering $\mathrm{n}^{\circ} 2 \mathrm{~B}$ does not provide any results, a new filtering will be carried out with the aim of being able to conduct a detailed analysis. As not all the criteria exert the same influence equally when searching for locations to host onshore wind farms, a new filtering process will be carried out based on the criteria that have higher coefficients of importance. In the case of wind farm location, the wind speed criterion $\left(g_{10}\right)$ plays a fundamental role [60]; its importance with respect to the other criteria is very high (Table 4 ).

Therefore, the last filtering will consist of taking the alternatives obtained in filtering $\mathrm{n}^{\circ} 1$ and, discarding those that do not have the wind speed criterion in the best category i.e., those alternatives whose wind speed is less than $7 \mathrm{~m} / \mathrm{s}$ will be removed.

\subsection{ELECTRE-TRI}

The alternatives obtained after the application of the Lexicographic method will be compared with those obtained when applying the ELECTRE-TRI methodology.

For solving the proposed problem in this article, the database generated in gvSIG will be employed. In order to obtain a classification by categories and thus be able to make a comparison with the method described above, the ELECTRE-TRI methodology will be applied. To do so, the boundaries of categories will be defined in the same way as indicated in Table 3 and the rest of the necessary parameters will be defined in terms of these categories [58,60], also indicating whether the criteria are to maximize or minimize (Table 5).

\section{Results}

\subsection{Lexicographic order}

In order to perform the steps described in the methodology and taking into account the above analysis, filtering $\mathrm{n}^{\circ} 1$ was made, obtaining a significant reduction of alternatives since the 33,290 possible locations were reduced to 3670 alternatives (Fig. 7).

From the alternatives obtained, filtering $n^{\circ} 2 \mathrm{~A}$ described in the methodology was conducted with the aim of removing those alternatives which have any of their criteria in category 2, in this way, the 3670 alternatives decreased to only two alternatives (Fig. 8). The location (UTM Zone 30 coordinate system) and identification of these alternatives are shown in Table 6.

Analyzing both alternatives (Table 7 ) it is observed that the criteria of these alternatives are located in categories 3 and 4 although neither of them has all the criteria situated in the best category (category 4 ).

The results obtained after the second filtering allow to represent each of the alternatives obtained indicating the category (Cat.) in which it would be located depending on the value of each of the criteria (Table 8). These results indicate that the values of the criteria $g_{1}$ (agrological capacity), $g_{2}$ (slope), $g_{3}$ (area), and $g_{4}$ (distance to airports) are similar for both alternatives, in these criteria both alternatives ( $A_{9029}$ and $A_{9036}$ ) belong to category 3 or category 4, moreover, the values of these first four criteria, compared with the full range of each criterion, have no excessive differences. However, it is noteworthy that criteria $g_{5}$ (distance to roads) and $g_{10}$ (wind speed) are clearly favorable to the alternative $A_{9036}$ while the criterion $g_{7}$ (distance to cities) is favorable to the alternative $A_{9029}$. Analyzing the criteria $g_{6}$ (distance to power lines), $g_{8}$ (distance to electricity transformer substations), and $g_{9}$ (distance to mast) it is observed that the alternatives for both the criterion $g_{6}$ and the criterion $g_{8}$ are better when their values are small while, for $g_{9}$ the opposite happens, so if we look at the evaluation for these three criteria it may indicate that $A_{9029}$ is better than $A_{9036}$. Hence, regardless of the weights that could be granted to each of the criteria, it could be said that alternatives $A_{9029}$ and $A_{9036}$ have no excessive differences.

Since, according to Table 8 , neither of the two alternatives obtained have all their criteria in category 4 , filtering $\mathrm{n}^{\circ} 2 \mathrm{~B}$ did not provide any information so the last filtering described in the methodology (filtering $n^{\circ} 2$ C) was carried out. Applying that filter, the 3670 alternatives are reduced to only 12 alternatives whose situation is reflected in Fig. 9; their characteristics are summarized in Table 9.

Table 5

Setting parameters to apply the ELECTRE-TRI method.

\begin{tabular}{|c|c|c|c|c|c|c|c|c|c|c|}
\hline Profile & $g_{1}$ (Classes) & $g_{2}(\%)$ & $g_{3}\left(\mathrm{~m}^{2}\right)$ & $g_{4}(\mathrm{~m})$ & $g_{5}(\mathrm{~m})$ & $g_{6}(\mathrm{~m})$ & $g_{7}(\mathrm{~m})$ & $g_{8}(\mathrm{~m})$ & $g_{9}(\mathrm{~m})$ & $g_{10}(\mathrm{~m} / \mathrm{s})$ \\
\hline$b_{1}$ & 2 & -50 & 10000 & 7000 & -5000 & -5000 & 1000 & -5000 & 400 & 3,2 \\
\hline$b_{2}$ & 4 & -30 & 300000 & 20000 & -2000 & -1500 & 2000 & -1500 & 1000 & 5,5 \\
\hline$b_{3}$ & 7 & -15 & 1000000 & 35000 & -500 & -500 & 5000 & -500 & 4000 & 7 \\
\hline$k_{j}$ & 0.050 & 0.042 & 0.042 & 0.088 & 0.009 & 0.039 & 0.010 & 0.092 & 0.027 & 0.601 \\
\hline$q_{j}(b)$ & 1 & 1 & 5000 & 5000 & 10 & 10 & 500 & 200 & 100 & 3 \\
\hline$p_{j}(b)$ & 4 & 10 & 20000 & 10000 & 200 & 100 & 1500 & 2000 & 500 & 5 \\
\hline \multirow[t]{2}{*}{$v_{j}(b)$} & 6 & 30 & 800000 & 15000 & 5500 & 4000 & 6000 & 4500 & 3000 & 10 \\
\hline & MAX & MIN & MAX & MAX & MIN & MIN & MAX & MIN & MAX & MAX \\
\hline
\end{tabular}




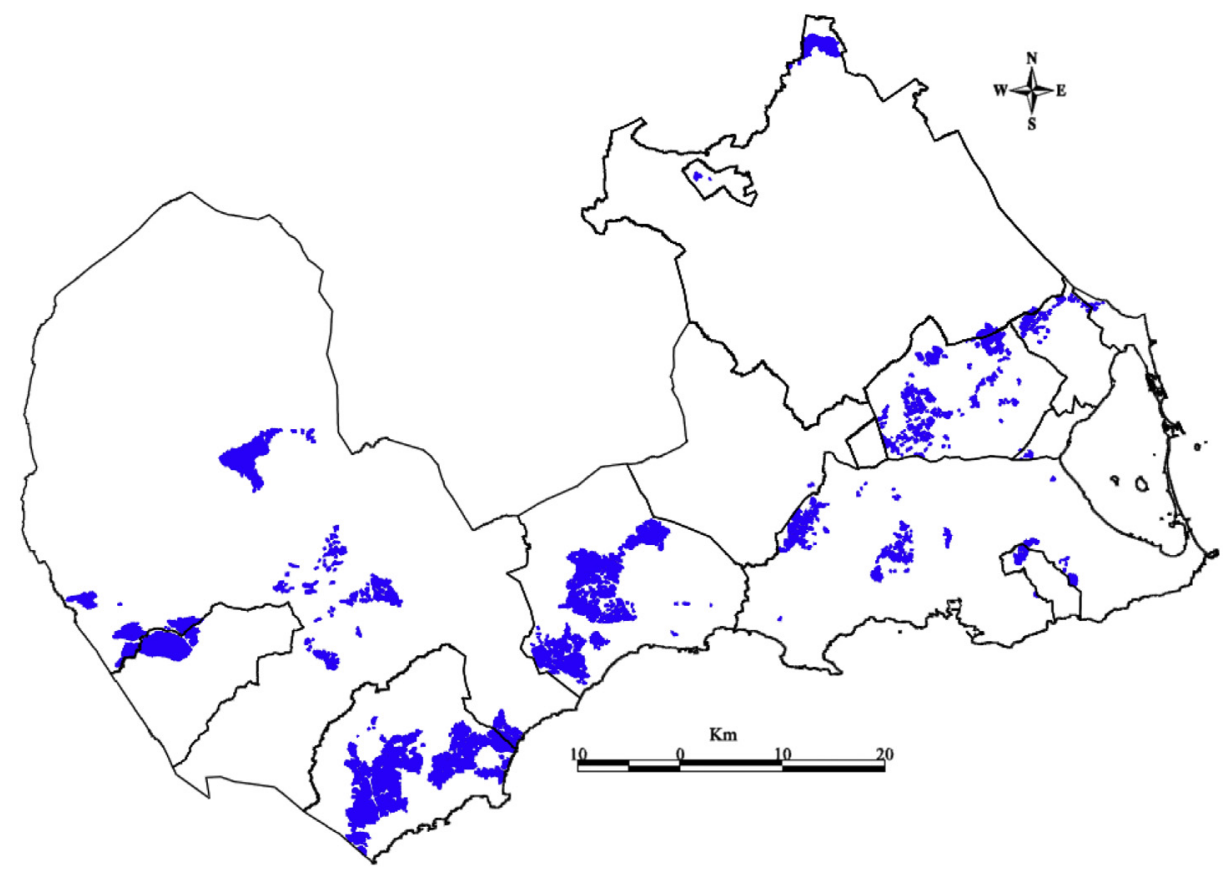

Fig. 7. Alternatives resulting after removing those alternatives with criteria in category 1 (filtering $\mathrm{n}^{\circ} 1$ ).

Analyzing the obtained alternatives (Table 9) it is observed that the alternative $A_{9029}$ in Table 7 has disappeared after filtering $\mathrm{n}^{\circ} 2 \mathrm{C}$, this is because in that alternative the wind speed (criterion $g_{10}$ ) has a value of $5.74 \mathrm{~m} / \mathrm{s}$, less than the minimum value that this criterion should have to be located in the best category $(7 \mathrm{~m} / \mathrm{s})$. The values of the criteria for such alternatives (Table 10) allow undertaking a deeper analysis.

Looking at the table above and taking into account the order of importance indicated in Table 4 , it is observed that if the best alternative is chosen based on the most important criterion $\left(g_{10}\right)$, this would be alternative $A_{32404}$. However, after the third filtering all the alternatives have this criterion situated in the best category $\left(A_{i} \geq 7 \mathrm{~m} / \mathrm{s}\right)$, there are minor differences between these alternatives for that criterion. Therefore, considering the selection process, the criteria with the next highest importance (criteria $g_{8}$ and $g_{4}$ ), it is observed that the best alternative is alternative $A_{9036}$ because, not only is it the one situated at a lower distance to transformer substations (criterion $g_{8}$ ) but it is also the farthest from the area of influence of airports (criterion $g_{4}$ ). For the same reasons the second best alternative is alternative $A_{9541}$. However, it is not clearly seen

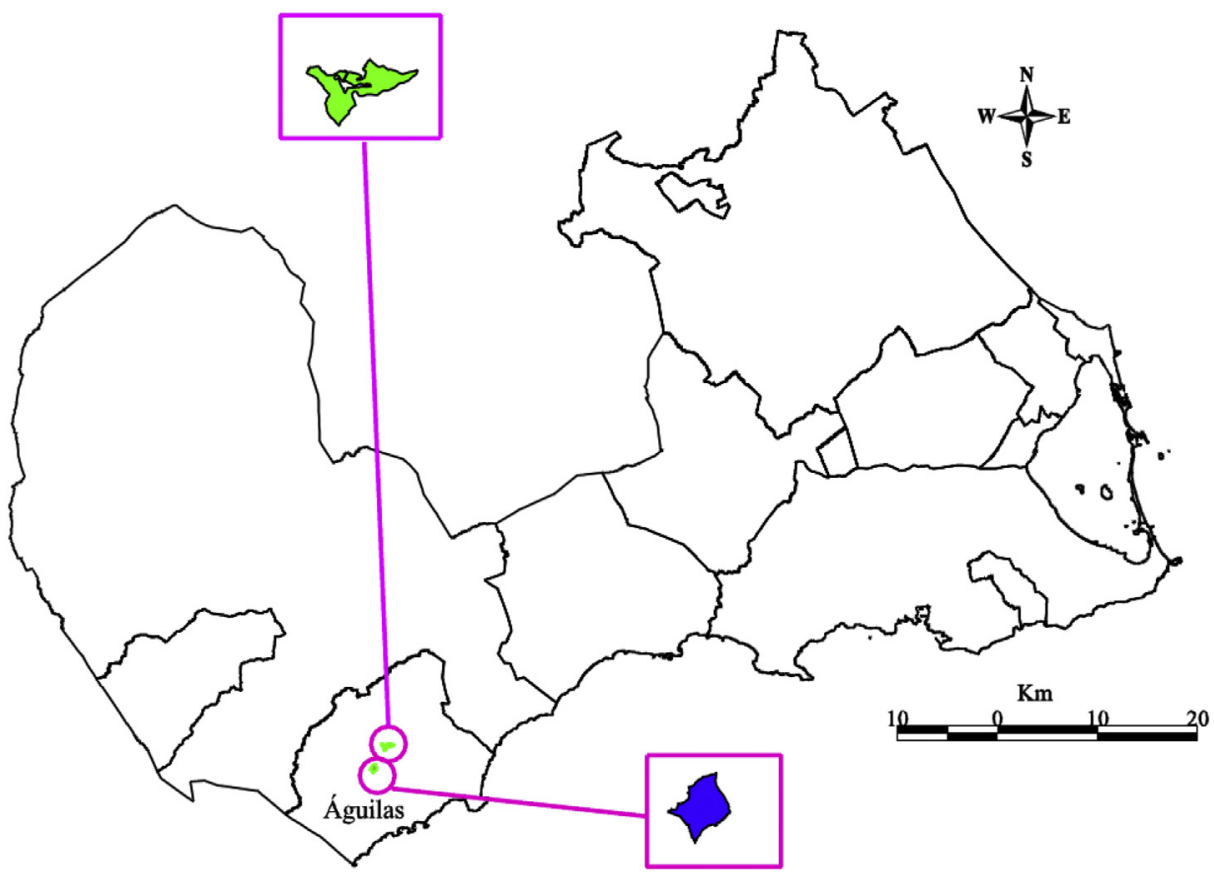

Fig. 8. Alternatives resulting after removing those alternatives with criteria in category 2 (filtering $n^{\circ} 2 A$ ). 
Table 6

Alternatives resulting after filtering $\mathrm{n}^{\circ} 2 \mathrm{~A}$

\begin{tabular}{lllllll}
\hline Alternatives & Municipalities & Zone & Plot & Subplot & Coord. $X$ & Coord. $Y$ \\
\hline$A_{9029}$ & Águilas & 044 & 00012 & a & 623573.00 & 4147258.04 \\
$A_{9036}$ & Águilas & 045 & 00019 & $\mathrm{~h}$ & 624763.00 & 4149198.21 \\
\hline
\end{tabular}

what the order of importance of the rest of the alternatives would be because although they have certain criteria that are favorable, additionally they have other criteria that are unfavorable. Nevertheless, it may be that for another expert or at another time the order of the weights would change. In that case Table 10 allows to obtain the best alternatives depending on each of the criteria, for example if the criterion $g_{1}$ (agrological capacity) is the most important, alternative $A_{32404}$ would be the best option. Yet, if it is desirable that the area to implement a wind farm has a minimum slope (criterion $g_{2}$ ), then the best alternative would be $A_{33017}$. Therefore these alternatives establish a Pareto front and depending on the conditions of the decision, the balance will shift toward one particular alternative or another so that, with this information, any promoter could opt for one alternative or another depending on the coefficient of importance given to each of the criteria.

Performing a global selection process i.e., selecting the best alternatives depending on the number of criteria that are located in the best category, it would be possible to represent (Table 11) each of the alternatives obtained indicating the category (Cat.) in which they would be located depending on the value of each criterion. With this selection process it is observed that alternatives $A_{8457}$,

Table 7

Criteria values in alternatives resulting after performing filtering $\mathrm{n}^{\circ} 2 \mathrm{~A}$

\begin{tabular}{|c|c|c|c|c|c|c|c|c|c|c|}
\hline \multirow[t]{3}{*}{ Alternatives } & \multicolumn{10}{|c|}{ Criteria } \\
\hline & $g_{1}$ & $g_{2}$ & $g_{3}$ & $g_{4}$ & $g_{5}$ & $g_{6}$ & $g_{7}$ & $g_{8}$ & $g_{9}$ & $g_{10}$ \\
\hline & Max. & Min. & Max. & Max. & Min. & Min. & Max. & Min. & Max. & Max. \\
\hline$A_{9029}$ & 4.50 & 16.67 & 360307.85 & 53008.24 & 1118.01 & 1302.60 & 5268.33 & 860.15 & 3140.07 & 5.74 \\
\hline$A_{9036}$ & 4.67 & 17.19 & 399225.23 & 50258.99 & 78.11 & 997.17 & 2831.47 & 997.17 & 1199.82 & 7.29 \\
\hline
\end{tabular}

Table 8

Categories of alternatives based on the values for each criterion after performing filtering $\mathrm{n}^{\circ} 2 \mathrm{~A}$.

\begin{tabular}{|c|c|c|c|c|c|c|c|c|c|c|}
\hline \multirow{2}{*}{ Alternatives } & \multicolumn{10}{|c|}{ Criteria } \\
\hline & $g_{1}$ & $g_{2}$ & $g_{3}$ & $g_{4}$ & $g_{5}$ & $g_{6}$ & $g_{7}$ & $g_{8}$ & $g_{9}$ & $g_{10}$ \\
\hline$A_{9029}$ & Cat. 3 & Cat. 3 & Cat. 3 & Cat. 4 & Cat. 3 & Cat. 3 & Cat. 4 & Cat. 3 & Cat. 3 & Cat. 3 \\
\hline$A_{9036}$ & Cat. 3 & Cat. 3 & Cat. 3 & Cat. 4 & Cat. 4 & Cat. 3 & Cat. 3 & Cat. 3 & Cat. 3 & Cat. 4 \\
\hline
\end{tabular}

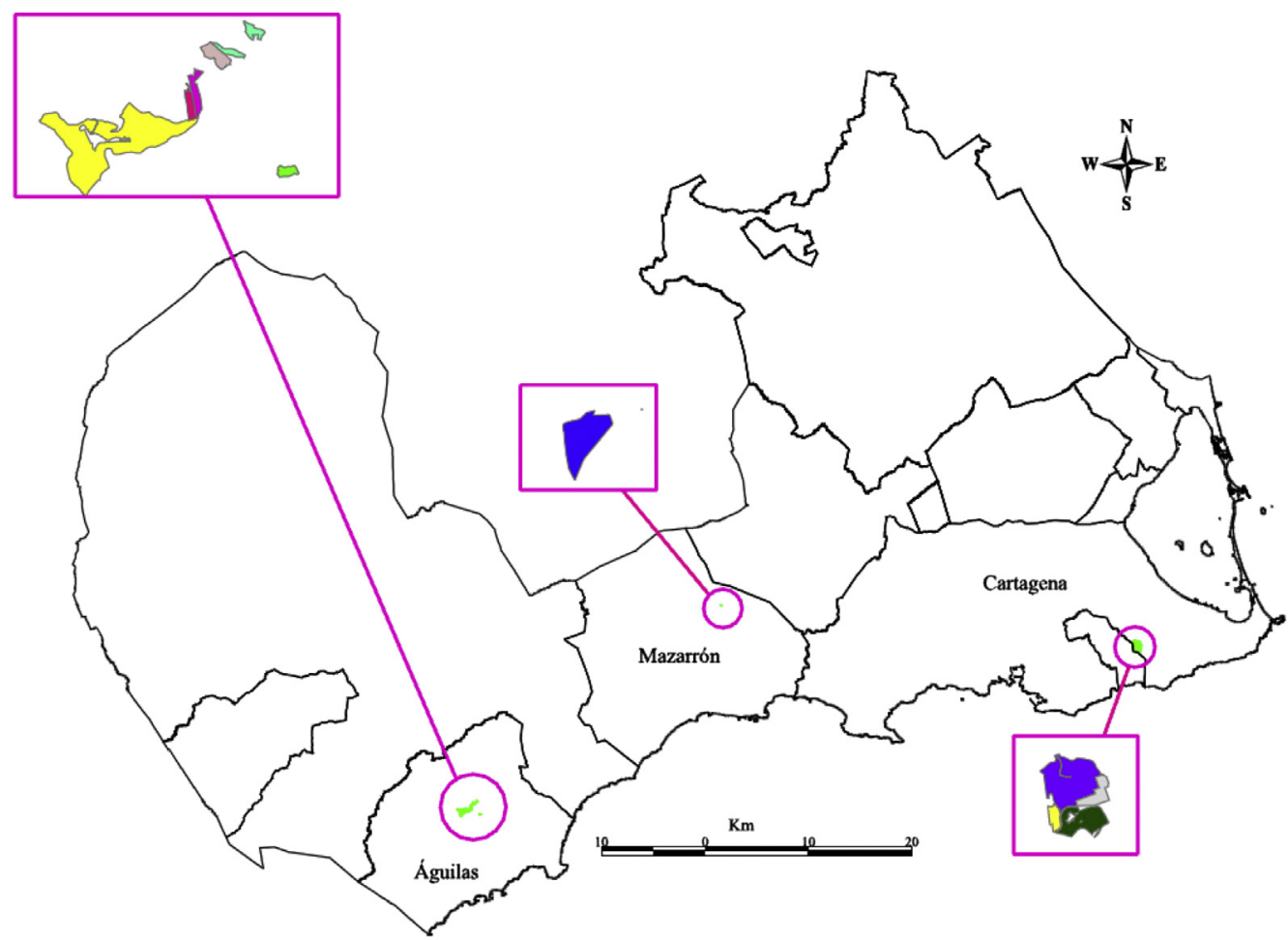

Fig. 9. Alternatives resulting after filtering depending on the wind speed (filtering $\mathrm{n}^{\circ} 2 \mathrm{C}$ ). 
Table 9

Alternatives resulting after filtering $\mathrm{n}^{\circ} 2 \mathrm{C}$.

\begin{tabular}{lllllll}
\hline Alternatives & Municipalities & Zone & Plot & Subplot & Coord. $X$ & Coord. $Y$ \\
\hline$A_{4238}$ & Mazarrón & 035 & 00023 & $\mathrm{~g}$ & 649758.50 & 4169166.22 \\
$A_{7753}$ & Águilas & 045 & 00046 & $\mathrm{a}$ & 625914.66 & 4150167.56 \\
$A_{8457}$ & Águilas & 045 & 00036 & $\mathrm{a}$ & 626150.44 & 4150357.69 \\
$A_{8943}$ & Águilas & 045 & 00056 & $\mathrm{~b}$ & 625624.97 & 4149799.18 \\
$A_{9036}$ & Águilas & 045 & 00019 & $\mathrm{~h}$ & 624763.00 & 4149198.21 \\
$A_{9541}$ & Águilas & 045 & 00053 & $\mathrm{~d}$ & 625568.05 & 4149743.59 \\
$A_{9870}$ & Águilas & 045 & 00047 & $\mathrm{a}$ & 625805.53 & 4150152.33 \\
$A_{9880}$ & Águilas & 045 & 00064 & $\mathrm{p}$ & 626756.61 & 4149122.60 \\
$A_{32078}$ & Cartagena & 046 & 00005 & $\mathrm{c}$ & 689639.11 & 4164985.22 \\
$A_{32404}$ & Cartagena & 046 & 00004 & $\mathrm{a}$ & 690157.78 & 4164645.00 \\
$A_{32405}$ & Cartagena & 046 & 00005 & $\mathrm{a}$ & 689855.48 & 4165483.77 \\
$A_{33017}$ & Cartagena & 046 & 00031 & $\mathrm{a}$ & 690181.63 & 4165232.43 \\
\hline & & & & & &
\end{tabular}

$A_{8943}$ and $A_{9541}$ are alternatives which have a larger number of criteria situated in the best category. However, alternative $A_{9036}$ stands out above the rest because, although it has fewer criteria situated in the best category (category 4 ) than alternatives $A_{8457}$, $A_{8943}$ and $A_{9541}$ the rest of its criteria are situated in the second best category (category 3 ).

\subsection{ELECTRE TRI}

Developing each of the steps in the ELECTRE-TRI methodology a classification of four categories (cat 1 , cat 2 , cat 3 , cat 4 ) will be obtained according to the aptitude or capacity to host a wind farm (regular, good, very good, and excellent capacity, respectively). As a result no alternatives located in the best category (cat. 4) are obtained, with 325 alternatives located in the second best category (cat. 3) of which the first 15 have been ordered according to the degree of credibility downstream (Table 12). To make the comparison of this methodology with the lexicographic order (Tables 8 and 11) the best 15 alternatives obtained by ELECTRE-TRI ordered according to the category to which each of their criteria will be represented (Table 13).

\subsection{Comparative lexicographic order vs. ELECTRE-TRI}

It is well known that the lexicographic order for the assessment takes into account only certain conditions of some criteria, and usually part of which are taken into account, while MCDM and particularly ELECTRE-TRI consider all the criteria.

Table 10

Criteria values of alternatives resulting after performing filtering $\mathrm{n}^{\circ} 2 \mathrm{C}$.

\begin{tabular}{|c|c|c|c|c|c|c|c|c|c|c|}
\hline \multirow[t]{3}{*}{ Alternatives } & \multicolumn{10}{|c|}{ Criteria } \\
\hline & $g_{1}$ & $g_{2}$ & $g_{3}$ & $g_{4}$ & $g_{5}$ & $g_{6}$ & $g_{7}$ & $g_{8}$ & $g_{9}$ & $g_{10}$ \\
\hline & Max. & Min. & Max. & Max. & Min. & Min. & Max. & Min. & Max. & Max. \\
\hline$A_{4238}$ & 5.33 & 13.28 & 10646.50 & 19155.61 & 25.00 & 1604.95 & 2075.20 & 4190.21 & 2999.93 & 7.05 \\
\hline$A_{7753}$ & 5.40 & 15.12 & 12919.78 & 49571.35 & 250.14 & 879.54 & 4495.30 & 2641.97 & 599.24 & 7.18 \\
\hline$A_{8457}$ & 4.67 & 13.81 & 15399.82 & 49298.48 & 145.10 & 693.26 & 4825.61 & 2884.83 & 440.24 & 7.23 \\
\hline$A_{8943}$ & 6.00 & 22.61 & 25718.48 & 49949.72 & 419.83 & 1281.80 & 6030.59 & 2019.60 & 999.50 & 7.27 \\
\hline$A_{9036}$ & 4.67 & 17.19 & 399225.23 & 50258.99 & 78.11 & 997.17 & 2831.47 & 997.17 & 1199.82 & 7.29 \\
\hline$A_{9541}$ & 6.00 & 18.95 & 16963.76 & 50128.72 & 450.57 & 1435.40 & 6038.54 & 1972.06 & 1150.28 & 7.09 \\
\hline$A_{9870}$ & 5.50 & 18.75 & 30086.45 & 49693.07 & 251.13 & 1012.00 & 4401.60 & 2510.19 & 730.86 & 7.10 \\
\hline$A_{9880}$ & 3.50 & 17.52 & 14593.04 & 49913.73 & 1418.79 & 1273.64 & 5075.18 & 2184.36 & 996.13 & 7.27 \\
\hline$A_{32078}$ & 3.33 & 22.55 & 45868.47 & 17178.18 & 4793.76 & 308.85 & 1775.27 & 2418.76 & 401.06 & 7.11 \\
\hline$A_{32404}$ & 6.90 & 13.24 & 185616.35 & 17161.40 & 4310.72 & 482.71 & 1373.55 & 2636.37 & 570.80 & 7.83 \\
\hline$A_{32405}$ & 4.86 & 21.31 & 398260.66 & 16513.23 & 4040.35 & 52.61 & 1006.22 & 2162.32 & 424.52 & 7.12 \\
\hline$A_{33017}$ & 2.50 & 12.22 & 85605.63 & 16723.62 & 4015.01 & 659.64 & 1007.63 & 2747.61 & 790.28 & 7.60 \\
\hline
\end{tabular}

Values in bold correspond to the best value for each criterion.

Table 11

Categories of alternatives based on the values for each criterion after performing filtering $\mathrm{n}^{\circ} 2 \mathrm{C}$

\begin{tabular}{|c|c|c|c|c|c|c|c|c|c|c|}
\hline \multirow{2}{*}{ Alternatives } & \multicolumn{10}{|c|}{ Criteria } \\
\hline & $g_{1}$ & $g_{2}$ & $g_{3}$ & $g_{4}$ & $g_{5}$ & $g_{6}$ & $g_{7}$ & $g_{8}$ & $g_{9}$ & $g_{10}$ \\
\hline $\mathrm{A}_{4238}$ & Cat. 3 & Cat. 4 & Cat. 2 & Cat. 2 & Cat. 4 & Cat. 2 & Cat. 3 & Cat. 2 & Cat. 3 & Cat. 4 \\
\hline$A_{7753}$ & Cat. 3 & Cat. 3 & Cat. 2 & Cat. 4 & Cat. 4 & Cat. 3 & Cat. 3 & Cat. 2 & Cat. 2 & Cat. 4 \\
\hline $\mathrm{A}_{8457}$ & Cat. 3 & Cat. 4 & Cat. 2 & Cat. 4 & Cat. 4 & Cat. 3 & Cat. 3 & Cat. 2 & Cat. 2 & Cat. 4 \\
\hline $\mathrm{A}_{8943}$ & Cat. 3 & Cat. 3 & Cat. 2 & Cat. 4 & Cat. 4 & Cat. 3 & Cat. 4 & Cat. 2 & Cat. 2 & Cat. 4 \\
\hline $\mathrm{A}_{9036}$ & Cat. 3 & Cat. 3 & Cat. 3 & Cat. 4 & Cat. 4 & Cat. 3 & Cat. 3 & Cat. 3 & Cat. 3 & Cat. 4 \\
\hline$A_{9541}$ & Cat. 3 & Cat. 3 & Cat. 2 & Cat. 4 & Cat. 4 & Cat. 3 & Cat. 4 & Cat. 2 & Cat. 3 & Cat. 4 \\
\hline $\mathrm{A}_{9870}$ & Cat. 3 & Cat. 3 & Cat. 2 & Cat. 4 & Cat. 4 & Cat. 3 & Cat. 3 & Cat. 2 & Cat. 2 & Cat. 4 \\
\hline $\mathrm{A}_{9880}$ & Cat. 2 & Cat. 3 & Cat. 2 & Cat. 4 & Cat. 3 & Cat. 3 & Cat. 4 & Cat. 2 & Cat. 2 & Cat. 4 \\
\hline $\mathrm{A}_{32078}$ & Cat. 2 & Cat. 3 & Cat. 2 & Cat. 2 & Cat. 2 & Cat. 4 & Cat. 2 & Cat. 2 & Cat. 2 & Cat. 4 \\
\hline $\mathrm{A}_{32404}$ & Cat. 3 & Cat. 4 & Cat. 2 & Cat. 2 & Cat. 2 & Cat. 4 & Cat. 2 & Cat. 2 & Cat. 2 & Cat. 4 \\
\hline$A_{32405}$ & Cat. 3 & Cat. 3 & Cat. 3 & Cat. 2 & Cat. 2 & Cat. 4 & Cat. 2 & Cat. 2 & Cat. 2 & Cat. 4 \\
\hline $\mathrm{A}_{33017}$ & Cat. 2 & Cat. 4 & Cat. 2 & Cat. 2 & Cat. 2 & Cat. 3 & Cat. 2 & Cat. 2 & Cat. 2 & Cat. 4 \\
\hline
\end{tabular}


Table 12

The best 15 alternatives according to the ELECTRE-TRI method.

\begin{tabular}{|c|c|c|c|c|c|c|c|c|c|c|}
\hline \multirow[t]{2}{*}{ Alternatives } & \multicolumn{10}{|c|}{ Criteria } \\
\hline & $g_{1}$ & $g_{2}$ & $g_{3}$ & $g_{4}$ & $g_{5}$ & $g_{6}$ & $g_{7}$ & $g_{8}$ & $g_{9}$ & $g_{10}$ \\
\hline$A_{9036}$ & 4.67 & 17.19 & 399225.23 & 50258.99 & 78.11 & 997.17 & 2831.47 & 997.17 & 1199.82 & 7.29 \\
\hline$A_{9029}$ & 4.50 & 16.67 & 360307.85 & 53008.24 & 1118.01 & 1302.60 & 5268.33 & 860.15 & 3140.07 & 5.74 \\
\hline$A_{3850}$ & 4.40 & 8.61 & 337117.60 & 33036.51 & 1175.75 & 1.00 & 3362.42 & 491.90 & 6141.50 & 5.37 \\
\hline$A_{9942}$ & 5.00 & 16.73 & 482241.24 & 52427.89 & 272.05 & 337.93 & 1663.64 & 546.27 & 3297.11 & 6.66 \\
\hline$A_{8389}$ & 4.62 & 6.55 & 300661.56 & 52218.25 & 25.00 & 1.00 & 1332.85 & 1354.54 & 3437.50 & 5.85 \\
\hline$A_{8991}$ & 4.75 & 23.44 & 293205.66 & 51534.25 & 512.34 & 315.95 & 2512.24 & 315.95 & 2456.57 & 6.76 \\
\hline$A_{8011}$ & 3.85 & 3.18 & 862128.86 & 44599.89 & 973.37 & 1.00 & 997.41 & 769.44 & 6386.01 & 5.66 \\
\hline$A_{9278}$ & 2.91 & 3.27 & 392545.04 & 44457.42 & 882.42 & 1.00 & 1092.47 & 1632.05 & 6757.53 & 5.67 \\
\hline$A_{8292}$ & 2.75 & 2.39 & 374412.20 & 47040.56 & 622.77 & 1.00 & 1304.19 & 344.06 & 5177.95 & 5.62 \\
\hline$A_{32052}$ & 6.94 & 7.59 & 323247.32 & 15240.66 & 25.00 & 1.00 & 817.45 & 1685.17 & 917.97 & 6.47 \\
\hline$A_{31012}$ & 6.00 & 14.43 & 352604.04 & 19192.02 & 118.38 & 255.83 & 584.07 & 1494.42 & 1348.48 & 7.20 \\
\hline$A_{5980}$ & 5.67 & 10.52 & 294113.47 & 26568.74 & 404.76 & 402.23 & 828.13 & 1254.39 & 2970.64 & 5.84 \\
\hline$A_{6976}$ & 4.71 & 10.61 & 355798.52 & 26799.04 & 963.55 & 976.37 & 575.56 & 1652.43 & 3186.09 & 5.83 \\
\hline$A_{9322}$ & 3.36 & 3.24 & 720038.29 & 45418.70 & 445.53 & 1.00 & 467.52 & 410.86 & 5947.77 & 5.73 \\
\hline$A_{9106}$ & 2.67 & 20.25 & 381671.37 & 54151.10 & 1670.96 & 789.06 & 4264.53 & 2049.96 & 3258.08 & 5.77 \\
\hline
\end{tabular}

As has been stated they are two alternative methods to obtain the best results. Using ELECTRE-TRI an overall assessment of the alternatives will be obtained through four categories, and within these categories according to the degree of credibility $\sigma_{S}$ a ranking will be obtained; this does not happen with the lexicographic order, which obtains some results that are in the same order.

Comparing initially the filtering process $2 \mathrm{~A}$ (Table 8) with the results obtained by ELECTRE-TRI (Table 13) it is observed that the two alternatives obtained after this filtering process ( $A_{9036}$ and $\left.A_{9029}\right)$ are located in the first two positions according to ELECTRE-TRI.

However, if the results obtained with the filtering process $2 \mathrm{C}$ (Table 11) are compared with those obtained by ELECTRE-TRI (Table 13) it is observed that there is no matching alternative; one of the reasons for this is because some of the best valued alternatives by ELECTRE-TRI have a criterion located in the worst category (category 1), so they had been discarded in the filtering process $n^{\circ} 1$. It is also noteworthy that although the goal of the filtering process $2 \mathrm{C}$ was to discard those alternatives that did not have the best valued criterion (wind speed) situated in the best category (category 4), it is observed that of the 15 best alternatives obtained in ELECTRE-TRI, although two of them have that criterion in the best category, most of them situate it in category 3.

\section{Conclusions}

Through the study performed, it has been shown that GIS software are excellent tools to resolve and display complex issues of localization, and that they can also generate important databases which provide an ideal starting point to solve any issues of a territorial nature.

In the particular case proposed different conclusions were reached; in relation to obtaining viable locations to implement onshore wind farms (Fig. 4), it has been concluded that the coast of the Region of Murcia is an optimal area to host this type of facilities because, once all the restrictions have been considered, a high percentage of suitable areas is obtained (19.94\%).

Using the information provided by the experts, it has been possible to perform a search for and selection of the best locations to host this type of facilities, successfully reducing the initial

Table 13

Categories of the best alternatives through ELECTRE-TRI based on the values for each criterion.

\begin{tabular}{|c|c|c|c|c|c|c|c|c|c|c|c|}
\hline \multirow{2}{*}{ Alternatives } & \multicolumn{10}{|c|}{ Criteria } & \multirow{2}{*}{$\sigma_{S}$} \\
\hline & $g_{I}$ & $g_{2}$ & $g_{3}$ & $g_{4}$ & $g_{5}$ & $g_{6}$ & $g_{7}$ & $g_{8}$ & $g_{9}$ & $g_{10}$ & \\
\hline $\mathrm{A}_{9036}$ & Cat. 3 & Cat. 3 & Cat. 3 & Cat. 4 & Cat. 4 & Cat. 3 & Cat. 3 & Cat. 3 & Cat. 3 & Cat. 4 & 1 \\
\hline $\mathrm{A}_{9029}$ & Cat. 3 & Cat. 3 & Cat. 3 & Cat. 4 & Cat. 3 & Cat. 3 & Cat. 4 & Cat. 3 & Cat. 3 & Cat. 3 & 1 \\
\hline $\mathrm{A}_{3850}$ & Cat. 3 & Cat. 4 & Cat. 3 & Cat. 3 & Cat. 3 & Cat. 4 & Cat. 3 & Cat. 4 & Cat. 4 & Cat. 2 & 1 \\
\hline $\mathrm{A}_{9942}$ & Cat. 3 & Cat. 3 & Cat. 3 & Cat. 4 & Cat. 4 & Cat. 4 & Cat. 2 & Cat. 3 & Cat. 3 & Cat. 3 & 1 \\
\hline $\mathrm{A}_{8389}$ & Cat. 3 & Cat. 4 & Cat. 3 & Cat. 4 & Cat. 4 & Cat. 4 & Cat. 2 & Cat. 3 & Cat. 3 & Cat. 3 & 0.9983 \\
\hline $\mathrm{A}_{8991}$ & Cat. 3 & Cat. 3 & Cat. 2 & Cat. 4 & Cat. 3 & Cat. 4 & Cat. 3 & Cat. 4 & Cat. 3 & Cat. 3 & 0.9949 \\
\hline $\mathrm{A}_{8011}$ & Cat. 2 & Cat. 4 & Cat. 3 & Cat. 4 & Cat. 3 & Cat. 4 & Cat. 1 & Cat. 3 & Cat. 4 & Cat. 3 & 0.9949 \\
\hline $\mathrm{A}_{9278}$ & Cat. 2 & Cat. 4 & Cat. 3 & Cat. 4 & Cat. 3 & Cat. 4 & Cat. 2 & Cat. 2 & Cat. 4 & Cat. 3 & 0.9944 \\
\hline $\mathrm{A}_{8292}$ & Cat. 2 & Cat. 4 & Cat. 3 & Cat. 4 & Cat. 3 & Cat. 4 & Cat. 2 & Cat. 4 & Cat. 4 & Cat. 3 & 0.9938 \\
\hline $\mathrm{A}_{32052}$ & Cat. 3 & Cat. 4 & Cat. 3 & Cat. 2 & Cat. 4 & Cat. 4 & Cat. 1 & Cat. 2 & Cat. 2 & Cat. 3 & 0.9931 \\
\hline $\mathrm{A}_{31012}$ & Cat. 3 & Cat. 4 & Cat. 3 & Cat. 2 & Cat. 4 & Cat. 4 & Cat. 1 & Cat. 3 & Cat. 3 & Cat. 4 & 0.9908 \\
\hline $\mathrm{A}_{5980}$ & Cat. 3 & Cat. 4 & Cat. 2 & Cat. 3 & Cat. 4 & Cat. 4 & Cat. 1 & Cat. 3 & Cat. 3 & Cat. 3 & 0.9907 \\
\hline $\mathrm{A}_{6976}$ & Cat. 3 & Cat. 4 & Cat. 3 & Cat. 3 & Cat. 3 & Cat. 3 & Cat. 1 & Cat. 2 & Cat. 3 & Cat. 3 & 0.9907 \\
\hline $\mathrm{A}_{9322}$ & Cat. 2 & Cat. 4 & Cat. 3 & Cat. 4 & Cat. 4 & Cat. 4 & Cat. 1 & Cat. 4 & Cat. 4 & Cat. 3 & 0.9828 \\
\hline $\mathrm{A}_{9106}$ & Cat. 2 & Cat. 3 & Cat. 3 & Cat. 4 & Cat. 3 & Cat. 3 & Cat. 3 & Cat. 2 & Cat. 3 & Cat. 3 & 0.9765 \\
\hline
\end{tabular}


alternatives to merely a very small and manageable number of alternatives (Fig. 9).

Through multi criteria decision methodologies such as the ELECTRE-TRI method it has been possible to classify the best alternatives into categories and carry out a comparison with the lexicographic order method. It has been shown that to select alternatives through filtering techniques may cause the discarding of valid alternatives for solving the proposed problems.

Among the limitations that this study presents which could be included in possible future work, mention could be made to extending the case study to the entire national territory or to other areas in which it is desirable to implement onshore wind farms, as well as to increasing the number of renewable technologies to be implemented (photovoltaic, solar thermoelectric, biomass, biogas, etc.). It would also be interesting to combine GIS with other decision support tools such as for example multi criteria decision methods, in order to be able to evaluate the different locations available.

\section{Acknowledgments}

This work is partially supported by FEDER funds, the DGICYT and Junta de Andalucía under projects TIN2011-27696-C02-01 and P11TIC-8001, respectively.

\section{References}

[1] Arrhenius S. On the influence of carbonic acid in the air upon the temperature of the ground. Philosophical Magazine and Journal of Science 1896;5(41): 237-76.

[2] Working Group I. Climate change. In: Houghton JT, Jenkins GJ, Ephraums JJ, editors. The IPCC scientific assessment. Cambridge: Cambridge University Press; 1990.

[3] Working Group II. Climate change. In: McG Tegart WJ, Sheldon GW, Griffiths DC, editors. The IPCC impacts assessment. Camberra: Australian Government Publishing Service; 1990.

[4] Working Group III. Climate change. In: The IPCC response strategies. Island Press; 1990. World Meteorological Organization/United Nations Environment Program.

[5] United Nations. Report of the United Nations. Conference on environment and development. Rio declaration on envorinment and development; 1992. Rio de Janeiro.

[6] United Nations. Framework convention on climatic change: report of the conference of the parties on its third session. Adoption of the Kyoto protocol; 1997. Kyoto.

[7] United Nations Framework Convention on Climate Change. Message to parties: early submission of information and views. Bonn: United Nations Climate Change Secretariat; 2013.

[8] European Commission. Energy for the future: renewable sources of energy Green paper for a community strategy; 1996. Brussels.

[9] European Commission. Energy for the future: renewable sources of energy. White paper for a community strategy and action plan; 1997. Brussels.

[10] European Parliament. Directive 2009/28/EC of the European Parliament and of the Council of 23 April 2009 on the promotion of the use of energy from renewable sources and amending and subsequently repealing directives 2001/77/EC and 2003/30/EC. Official Journal of the European Union 2009. Brussels.

[11] Klass DL. A critical assessment of renewable energy usage in the USA. Energy Policy 2003;31:353-67.

[12] Espey S. Renewables portfolio standard: a means for trade with electricity from renewable energy sources. Energy Policy 2001;29:557-66.

[13] Menz FC, Vachon S. The effectiveness of different policy regimes for promoting wind power: experiences from the states. Energy Policy 2006;34: 1786-96.

[14] Lund H. Renewable energy strategies for sustainable development. Energy 2007;32:912-9.

[15] Wünteshagen R, Bilharz M. Green energy market development in Germany: effective public policy and emerging customer demand. Energy Policy 2006;34:1681-96.

[16] Frondel M, Ritter N, Schmidt CM, Vance V. Economic impacts from the promotion of renewable energy technologies: the German experience. Energy Policy 2010:38:4048-56.

[17] Bürer MJ, Wüstenhagen R. Which renewable energy policy is a venture capitalist's best friend? Empirical evidence from a survey of international cleantech investors. Energy Policy 2009;37:4997-5006.
[18] Wünteshagen R, Menichetti E. Strategic choices for renewable energy investment: conceptual framework and opportunities for further research. Energy Policy 2012;40:1-10.

[19] Institute for Energy Diversification and Saving IDAE. Renewable energies plan (PER) 2005-2010. Madrid: Ministry of Industry, Tourism and Commerce; 2005.

[20] Institute for Energy Diversification and Saving IDAE. Renewable energies plan (PANER) 2011-2020. Madrid: Ministry of Industry, Tourism and Commerce; 2010.

[21] The European Wind Energy Association EWEA. Wind in power 2010 European statistics; 2010.

[22] BOE n 24 Royal Decree-Law 1/2012, of 27 January, in which proceeded to suspend pre-allocation procedures and the removal of economic incentives for new facilities of electricity production from cogeneration, renewable energies and waste. Madrid: Ministry of Industry, Energy and Tourism; 2012.

[23] The European Wind Energy Association EWEA. Wind in power 2012 European statistics; 2012.

[24] Burgos-Payán M, Roldán-Fernández JM, Trigo-García AL, Bermúdez-Ríos JM, Riquelme-Santos JM. Costs and benefits of the renewable production of electricity in Spain. Energy Policy 2013;56:259-70.

[25] Gómez A, Zubizarreta J, Dopazo C, Fueyo N. Spanish energy roadmap to 2020: socioeconomic implications of renewable targets. Energy 2011;36: 1973-85.

[26] Institute for Energy Diversification and Saving IDAE. Wind resource study and development of a wind map of Spain. Madrid: Ministry of Industry, Tourism and Commerce; 2010.

[27] Gómez-López MD, García-Cascales MS, Ruiz Delgado E. Situations and problems of renewable energy in the Region of Murcia, Spain. Renewable and Sustainable Energy Reviews 2010;14:1253-62.

[28] Rehman S, Al-Abbadi NM. Wind shear coefficients and their effect on energy production. Energy Conversion and Management 2005;46:2578-91.

[29] Rehman S, Al-Abbadi NM. Wind shear coefficient, turbulence intensity and wind power potential assessment for Dhulom, Saudi Arabia. Renewable Energy 2008;33:2653-60.

[30] Bagiorgas HS, Mihalakakou G, Rehman S, Al-Hadhrami LM. Weibull parameters estimation using four different methods and most energy carrying wind speed analysis. International Journal of Green Energy 2011;8:529-54.

[31] Rehman S, Ahmad A, El-Amin I, Al-Hadhrami LM. Assessment of wind power, wind exponent, local air density and air turbulence intensity for an isolated site. International Journal of Sustainable Energy 2009;28:217-30.

[32] San Cristobal JR. A multi criteria data envelopment analysis model to evaluate the efficiency of the renewable energy technologies. Renewable Energy 2011:36:2742-6.

[33] Huang JP, Poh KL, Ang BW. Decision analysis in energy and environmental modeling. Energy 1995;20(9):843-55.

[34] Georgopoulou E, Lalas D, Papagiannakis L. A multicriteria decision aid approach for energy planning problems: the case of renewable energy option. European Journal of Operational Research 1997;103:38-54.

[35] Ulutas BH. Determination of the appropriate energy policy for Turkey. Energy 2005;30:1146-61.

[36] Kahraman C, Kaya I, Cebi S. A comparative analysis for multiattribute selection among renewable energy alternatives using fuzzy axiomatic design and fuzzy analytic hierarchy process. Energy 2009;34:1603-16.

[37] Kaya T, Kahraman C. Multicriteria renewable energy planning using an integrated fuzzy VIKOR \& AHP methodology: the case of Istanbul. Energy 2010;35:2517-27.

[38] Scott JA, Ho W, Dey PK. A review of multi-criteria decision-making methods for bioenergy systems. Energy 2012;42:146-56.

[39] García-Cascales MS, Lamata MT, Sánchez-Lozano JM. Evaluation of photovoltaic cells in a multi-criteria decision making process. Annals of Operations Research 2012;199:373-91.

[40] Choudhary D, Shankar R. An STEEP-fuzzy AHP-TOPSIS framework for evaluation and selection of thermal power plant location: a case study from India. Energy 2012;42:510-21.

[41] Malczewski J. 392pp. GIS and multicriteria decision analysis. New York: J. Wiley \& Sons; 1999.

[42] Uyan M. GIS-based solar farms site selection using analytic hierarchy process (AHP) in Karapinar region, Konya/Turkey. Renewable and Sustainable Energy Reviews 2013;28:11-7.

[43] Voivontas D, Assimacopoulos D, Mourelatos A. Evaluation of renewable energy potential using a GIS decisión support system. Renewable Energy 1998:13(3):333-44.

[44] Tüfekçi N, Süzen ML, Güleç N. GIS based geothermal potential assessment: a case study from Western Anatolia, Turkey. Energy 2010;35:246-61.

[45] Hong L, Möller B. Offshore wind energy potential in China: under technical, spatial and economic constraints. Energy 2011;36:4482-91.

[46] Kaundinya DP, Balachandra P, Ravindranath NH, Ashok VAGIS. (geographical information system)-based spatial data mining approach for optimal location and capacity planning of distributed biomass power generation facilities: a case study of Tumkur district, India. Energy 2013;52:77-88.

[47] Hu MC, Huang AL, Wen TH. GIS-based biomass resource utilization for rice straw cofiring in the Taiwanese power market. Energy 2013;55:354-60.

[48] Al-Yahyai S, Charabi Y, Gastli A, Al-Badi A. Wind farm land suitability indexing using multi-criteria analysis. Renewable Energy 2012;44:80-7. 
[49] Aydin NY, Kentel E, Duzgun S. GIS-based environmental assessment of wind energy systems for spatial planning: a case study from Western Turkey. Renewable and Sustainable Energy Reviews 2010;14:364-73.

[50] Charabi Y, Gastli A. PV site suitability analysis using GIS-based spatial fuzzy multi-criteria evaluation. Renewable Energy 2011;36:2554-61.

[51] Zubaryeva A, Zaccarelli N, Del Giudice C, Zurlini G. Spatially explicit assessment of local biomass availability for distributed biogas production via anaerobic co-digestion. Mediterranean case study. Renewable Energy 2012;39:261-70.

[52] Arán-Carrión J, Espín-Estrella A, Aznar-Dols F, Zamorano-Toro M, Rodríguez M, Ramos-Ridao A. Environmental decision-support systems for evaluating the carrying capacity of land areas: optimal site selection for gridconnected photovoltaic power plants. Renewable and Sustainable Energy Reviews 2008;12:2358-80.

[53] Sánchez-Lozano JM, Teruel-Solano J, Soto-Elvira PL, García-Cascales MS. Geographical Information Systems (GIS) and Multi-Criteria Decision Making (MCDM) Methods for the evaluation of solar farms locations: case study in south-eastern Spain. Renewable and Sustainable Energy Reviews 2013;24: 544-56.

[54] Sánchez-Lozano JM, Antunes CH, García-Cascales MS, Dias LC. GIS-based photovoltaic solar farms site selection using ELECTRE-TRI: evaluating the case for Torre-Pacheco, murcia, southeast of Spain. Renewable Energy 2014;66: 478-94. 1016/j.renene.2013.12.038.

[55] Regional Ministry of Infrastructure and Transport of Valencia. gvSIG association, https://gvsig.org/web/catalog; [accessed 15.04.13].
[56] Roy B, Bouyssou D. Aide à la décision fondée sur une PAMC de type ELECTRE vol. 69. Université Paris-Dauphine; 1991. p. 118. Document du LAMSADE.

[57] European Parliament. Directive 92/43/EEC of 21 May 1992 on the conservation of natural habitats and of wild fauna and flora. Official Journal of the European Union 2009. Brussels.

[58] Sánchez-Lozano JM. Search and evaluation of optimal sites to implant renewable energies facilities, combination of geographic information systems (GIS) and soft computing: case study of the coast of the Region of Murcia. MS Thesis. Technical University of Cartagena; 2013. Available at: http://unicorn. bib.upct.es/uhtbin/cgisirsi/upct/SALA1/0/1/1306/X.

[59] Janke JR. Multicriteria GIS modeling of wind and solar farms in Colorado. Renewable Energy 2010;35:2228-34.

[60] Sánchez-Lozano JM, García-Cascales MS, Lamata MT, Sierra C. Decision criteria for optimal location of wind farms, exploring innovative and successful applications of soft computing. IGI Global Ed 2013:199-215. http://dx.doi.org/ 10.4018/978-1-4666-4785-5.ch011.

[61] Vincke P. Multicriteria decision-aid. Wiley; 1992.

[62] Keeny RL, Raiffa H. Decisions with multiple objectives: preferences and value tradeoff. Wiley; 1976

[63] Yu W. Aide multicritère à la décision dans le cadre de la problématique du tri. Concepts, méthodes et applications, Thèse de doctorat, UER Sciences de l'organisation. Université Paris-Dauphine; 1992. p. 201.

64] Yu W. ELECTRE TRI. Aspects méthodologiques et manuel d'utilisation, vol. 74 Université Paris-Dauphine; 1992. p. 80. Document du LAMSADE. 